\title{
Motor cortex arteriovenous malformation
}

\author{
Alfred P. See, MD, Bruno C. Flores, MD, Karam Moon, MD, Andrew F. Ducruet, MD, \\ Robert F. Spetzler, MD, and Felipe C. Albuquerque, MD
}

Department of Neurosurgery, Barrow Neurological Institute, St. Joseph's Hospital and Medical Center, Phoenix, Arizona

Supratentorial arteriovenous malformations in eloquent territories can be difficult to resect. This video presents the treatment of a patient with a symptomatic 3-cm arteriovenous malformation in the left motor strip. At the authors' institution, per the surgeon's discretion, preoperative angiography is performed to evaluate the need for preoperative embolization. Multimodality treatment reduced the microsurgical risk by allowing early occlusion of a draining vein, by decreasing overall intraoperative hemorrhage, and by allowing minimal pial dissection in the deep aspect of the arteriovenous malformation that abutted the corticospinal tract. The choice of embolysate was an additional nuance of the embolization.

The video can be found here: https://youtu.be/HWZORjgPEXg.

KEYWORDS arteriovenous malformation; eloquent cortex; preoperative embolization 